\title{
When to use intravascular ultrasound or optical coherence tomography during percutaneous coronary intervention?
}

\author{
Vinayak Nagaraja, Ankur Kalra, Rishi Puri \\ Department of Cardiovascular Medicine, Cleveland Clinic Foundation, Cleveland, OH, USA \\ Contributions: (I) Conception and design: R Puri; (II) Administrative support: None; (III) Provision of study materials or patients: None; (IV) \\ Collection and assembly of data: None; (V) Data analysis and interpretation: None; (VI) Manuscript writing: All authors; (VII) Final approval of \\ manuscript: All authors. \\ Correspondence to: Rishi Puri, MBBS, PhD. Department of Cardiovascular Medicine, Cleveland Clinic Foundation, 9500 Euclid Avenue, Mail Code \\ J2-3, Cleveland, OH 44195, USA. Email: purir@ccf.org.
}

\begin{abstract}
Intravascular ultrasound (IVUS) and optical coherence tomography (OCT) are intravascular imaging technologies widely used in the cardiac catheterization laboratory. The impact of these modalities for optimizing the acute and longer-term clinical impact following percutaneous coronary intervention (PCI) is supported by a wealth of clinical evidence. Intravascular imaging provides unique information for enhanced lesion preparation, optimal stent sizing, recognizing post PCI complications, and the etiology of stent failure. This review compares and contrasts the key aspects of these imaging modalities during PCI.
\end{abstract}

Keywords: Intravascular ultrasound (IVUS); optical coherence tomography (OCT); percutaneous coronary intervention (PCI); cardiovascular mortality; repeat revascularization

Submitted Feb 12, 2020. Accepted for publication Apr 20, 2020.

doi: $10.21037 / \mathrm{cdt}-20-206$

View this article at: http://dx.doi.org/10.21037/cdt-20-206

\section{Introduction}

Intravascular imaging guidance during percutaneous coronary intervention (PCI) significantly improves clinical outcomes $(1,2)$. Intravascular ultrasound (IVUS) and optical coherence tomography (OCT) are the two commercially available intravascular imaging technologies used to guide decision-making and optimize PCIs. Intravascular imaging guidance improves outcomes by adequately informing clinicians of true vessel size, landing zones to guide stent length selection, plaque morphology to guide debulking strategies, identify PCI complications (edge dissection, stent malapposition) and mechanisms of stent failure (stent thrombosis/under expansion/fracture, neointimal hyperplasia, neoatherosclerosis) (3-7). This review compares and contrasts the utility of IVUS and OCT in contemporary PCI, identifying appropriate situations for utilizing these contrasting imaging modalities.

\section{IVUS and OCT: technical and procedural differences}

IVUS utilizes ultrasound whereas the OCT uses infrared light (8-10). OCT has 10 times greater resolution compared with IVUS; however, it requires clearing of blood typically with contrast, but also with dextran as a contrast-sparing agent $(11,12)$. OCT has lower penetration $(1-2 \mathrm{~mm})$ compared with IVUS $(5-6 \mathrm{~mm})$. The quality of the OCT image worsens in presence of red thrombus (Figure 1). As a result of the short wavelength, red blood cells lead to 'structural noise,' and thus image distortion. Given the greater resolution of OCT, images are more reproducible compared with IVUS (13). On the other hand, IVUS provides visibility of all three arterial layers, its depth of penetration enables one to assess vascular remodeling which in turn more appropriately guides optimal vessel sizing enabling larger-sized stent implantation. OCT has a higher 

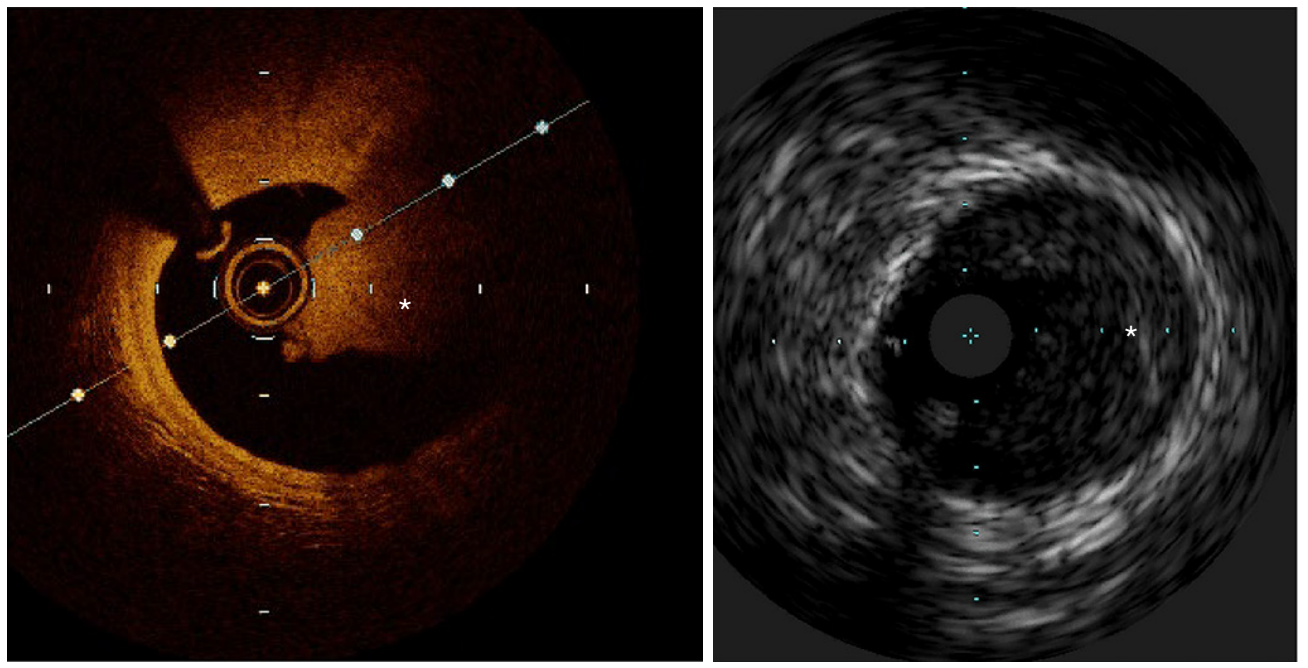

Figure 1 Red thrombus (white asterisk) on OCT and IVUS. OCT, optical coherence tomography; IVUS, intravascular ultrasound.

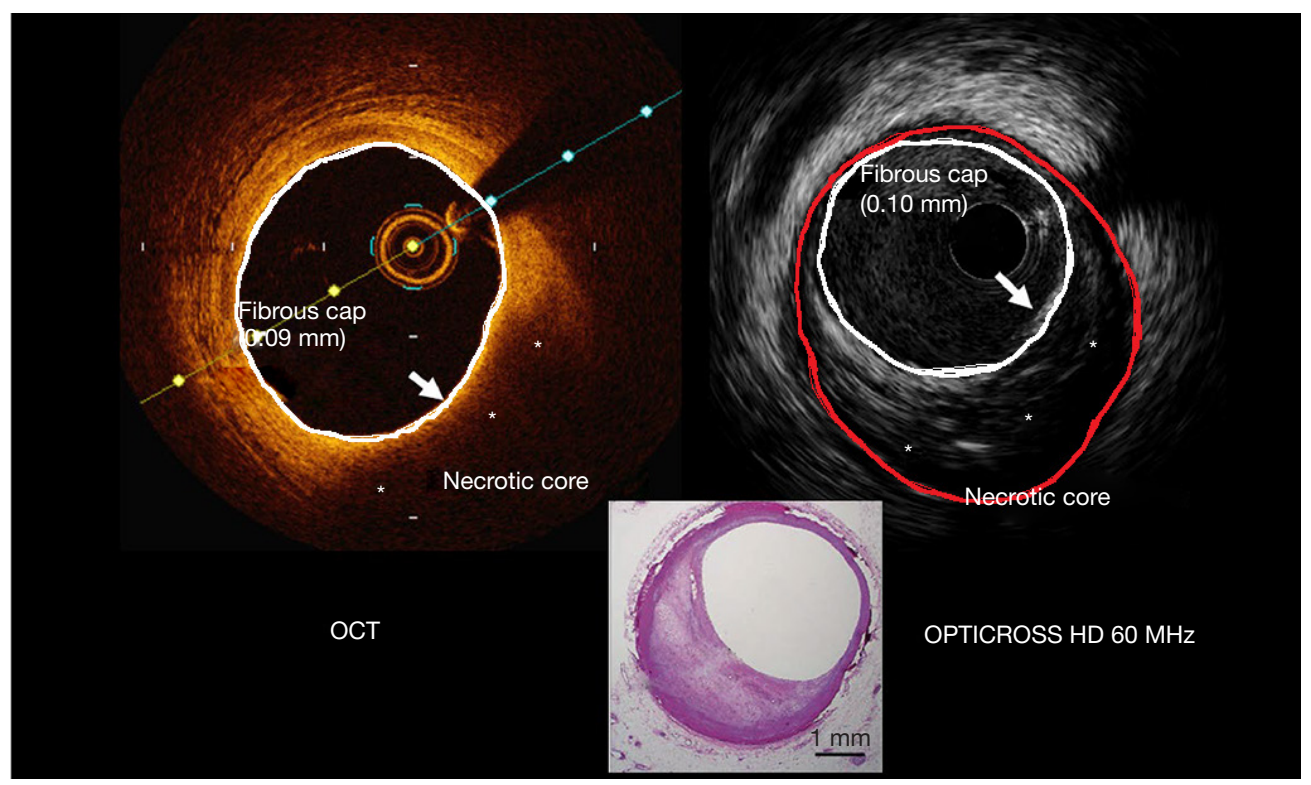

Figure 2 Thin fibrous plaque with a necrotic core on OCT and IVUS, courtesy Boston Scientific (white circles represent lumen area on the OCT/IVUS images, whereas the red circle represents the true vessel based on the EEM. The white asterisks represent the necrotic core). OCT, optical coherence tomography; IVUS, intravascular ultrasound.

resolution but has limited depth compared with IVUS. The resolution has improved with high definition-IVUS, true vessel size is much better appreciated on IVUS (Figure 2) compared with OCT for optimal stent selection. The commercially available devices are listed in Table 1 .

\section{Plaque morphological assessment}

Angiographic detection of coronary calcification is as low as $40 \%$ (14), but when visible, it corresponds to a greater calcific burden. When compared with anatomical pathology, IVUS has a sensitivity of nearly $90 \%$ and 
Table 1 Commercially available intravascular imaging modalities

\begin{tabular}{|c|c|c|c|c|c|c|c|}
\hline Imaging modality & Manufacturer & Source & $\begin{array}{c}\text { Axial } \\
\text { resolution }(\mu \mathrm{m})\end{array}$ & $\begin{array}{l}\text { Lateral } \\
\text { resolution }(\mu \mathrm{m})\end{array}$ & $\begin{array}{c}\text { Tissue } \\
\text { penetration }(\mathrm{mm})\end{array}$ & $\begin{array}{c}\text { Frame } \\
\text { width }(\mathrm{mm})\end{array}$ & $\begin{array}{c}\text { Pullback } \\
\text { distance }(\mathrm{mm})\end{array}$ \\
\hline \multirow{6}{*}{$\begin{array}{l}\text { Intravascular } \\
\text { ultrasound }\end{array}$} & Boston Scientific & $40 \mathrm{MHz}$ Ultrasound & 38 & $80-200$ & $>5$ & $0.02-0.03$ & 100 \\
\hline & Volcano & $20 \mathrm{MHz}$ Ultrasound & 170 & 100 & $>5$ & $0.02-0.03$ & 150 \\
\hline & Volcano & $45 \mathrm{MHz}$ Ultrasound & 46 & 179 & $>5$ & $0.02-0.03$ & 150 \\
\hline & Boston Scientific & $60 \mathrm{MHz}$ Ultrasound & 22 & $50-140$ & $>5$ & $0.02-0.03$ & 100 \\
\hline & ACIST & $60 \mathrm{MHz}$ Ultrasound & 40 & 90 & 3 & $0.02-0.17$ & 120 \\
\hline & Terumo & $60 \mathrm{MHz}$ Ultrasound & $<30$ & 100 & Not available & $0.02-0.1$ & 150 \\
\hline $\begin{array}{l}\text { Optical coherence } \\
\text { tomography }\end{array}$ & Abbott & Near Infrared $1.3 \mu \mathrm{m}$ & 15 & $20-40$ & 1 to 2 & $0.1-0.2$ & 75 \\
\hline
\end{tabular}

specificity ranging between $97-100 \%$ for identifying plaque calcification $(15,16)$. OCT allows for a more precise visualization and image penetration in calcific coronary disease compared with IVUS, given that calcium reflects ultrasound waves. OCT, therefore, enables more accurate information regarding calcium depth and regionality. PCI in extensive calcific coronary disease is challenging and impedes stent expansion in the absence of appropriate plaque modification pre-stenting (17). A calcification arc of $>180^{\circ}$ and depth $>0.5 \mathrm{~mm}$ thick are predictive of worse outcomes as a result of stent under-expansion and this finding on intravascular imaging should prompt the operator to consider adjunctive plaque modification strategies (such as cutting/scoring balloons and/or rotational atherectomy).

A Japanese study of 247 patients compared OCTguided rotational atherectomy with IVUS-guided rotational atherectomy (18). The results demonstrated significantly larger final burr size $(1.75$ vs. $1.50 \mathrm{~mm}, \mathrm{P}=0.001)$ and percent stent expansion ( $83 \%$ vs. $72 \%, \mathrm{P}=0.0004)$ used in the OCT-guided rotational atherectomy cohort compared with the IVUS-guided cohort. However, target lesion revascularization (TLR) rates were similar across the 2 cohorts. Intravascular imaging is essential in calcified coronary lesions and appropriate plaque modification in the form of atherectomy (laser/cutting or scoring balloon/ rotational/orbital atherectomy) is crucial in achieving adequate stent expansion.
Coronary intravascular lithotripsy balloons can be effectively used in circumferential calcific disease or in the presence of calcific arcs $>270^{\circ}$ arc based on OCT (19-22). A three-arm trial (NCT03574636) is currently underway comparing OCT with IVUS with quantitative coronary angiography during PCI for moderate-severely calcified lesions. The primary endpoint of the trial is in-stent late lumen loss (difference between the minimal lumen diameter immediately post PCI and the minimal lumen diameter by angiography review at 13 months post PCI). Figure 2 demonstrates circumferential calcification on OCT and IVUS.

Intravascular imaging using OCT or IVUS has been demonstrated to predict slow flow or no-reflow phenomena and subsequent peri-procedural myocardial infarction prior to stent implantation (23-26). The plaque characteristics predictive of these adverse outcomes included an attenuated plaque suggestive of a large necrotic core on IVUS (27) or acute plaque rupture or thin fibrous cap atheroma (Figure 3). An attenuated plaque with a longitudinal length of more than $5 \mathrm{~mm}$ on IVUS was associated with the ability to predict the no-reflow phenomenon (25). In an analysis of 336 individuals with acute coronary syndromes (ACS) (24), echo signal attenuated plaque was independently associated with no-reflow phenomena with an odds ratio of 5.59 (95\% CI: 2.64-11.85). Should these higher-risk features be identified on intravascular pre-PCI imaging, additional steps could be considered such as intracoronary enalaprilat (28) or distal filter protection device in an attempt to minimize 

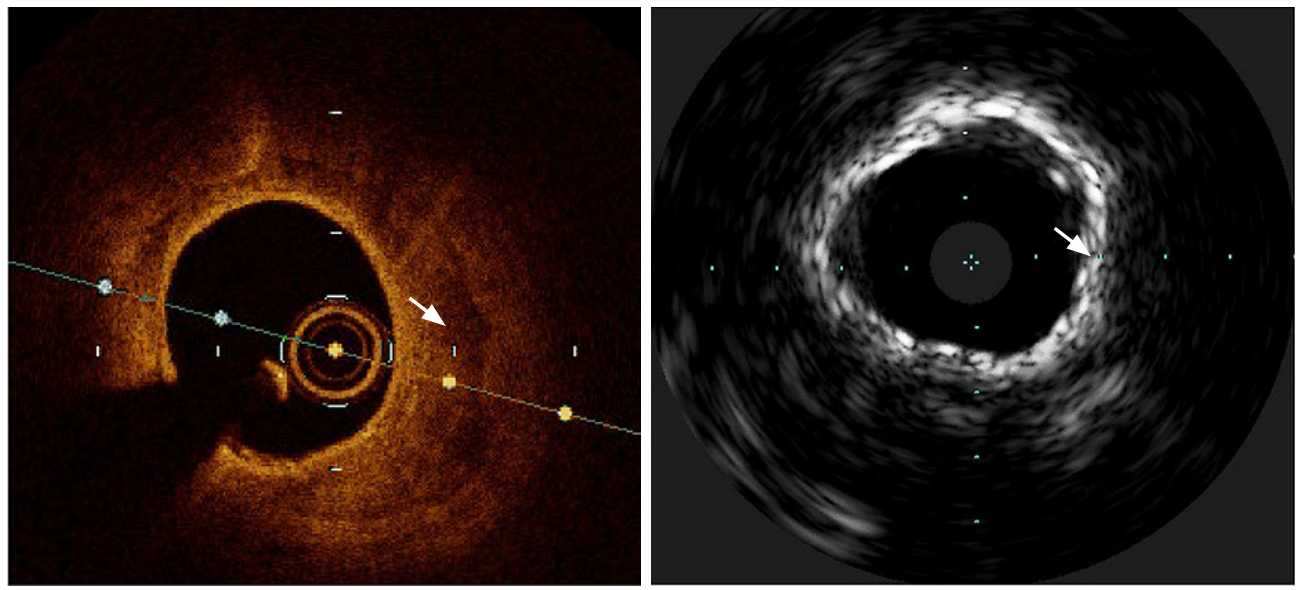

Figure 3 Circumferential calcification (white arrow) demonstrated on OCT and IVUS. OCT, optical coherence tomography; IVUS, intravascular ultrasound.

no-reflow and periprocedural myocardial infarction (29).

\section{Stent selection and optimization}

The Multicenter Ultrasound Stenting in Coronaries Study (MUSIC) (30) was the first major trial to provide criteria for bare-metal stent optimization. This included a minimum stent area (MSA) $\geq 90 \%$ of the average reference lumen area or $\geq 100 \%$ of the smaller reference lumen area; or an MSA $>9 \mathrm{~mm}^{2}$, with $\mathrm{MSA} \geq 80 \%$ of average reference lumen area or $\geq 90 \%$ of smaller reference lumen. Achievement of these criteria resulted in a reduced incidence of TLR at 6 months. In the drug-eluting stent era, external elastic membrane (EEM) diameters minus $0.5 \mathrm{~mm}$ of the distal vessel segment is used to choose the appropriate stent size and the proximal reference vessel diameter is sometimes used as the reference balloon size to post dilate the stent. The AVIO trial (5) suggested the final optimal MSA was based on the IVUSguided sized balloon area at nominal pressure. Table 2 summarizes the various IVUS stent optimization criteria. OCT-guided stent sizing is evolving and remains somewhat hampered by the difficulty in adequately visualizing the EEM across diseased segments.

\section{Post PCI complications}

Only $7 \%$ of angiographically normal-appearing vessels truly harbored no plaque on IVUS, and these regions typically contain significant plaque burden masked by the adaptive vessel remodeling response to plaque progression (37). Geographical miss is defined as an angiographically significantly diseased segment or (balloon) injured segment not treated by a stent (38). Geographical miss is linked to stent failure (restenosis and stent thrombosis) (39-41). Stent edge dissections and edge restenosis are frequently linked to greater stent edge plaque burden $(>50 \%)$ and the presence of calcium/attenuated plaque $(2,39,42)$. A dissection seen on IVUS resulting in a lumen area of $<5.0 \mathrm{~mm}^{2}$, with a length $>3$ $\mathrm{mm}$ and an arc $>60^{\circ}$ is significantly associated with the need for TLR (2) (Video 1). Based on the OCT literature, a distal edge dissection $>200 \mu \mathrm{m}$ and an MLA $<4.5 \mathrm{~mm}^{2}$ are linked with adverse clinical outcomes (43). On OCT, a lipid arc of $185^{\circ}$ and an MLA $<4.1 \mathrm{~mm}^{2}$ were related to edge restenosis (44). An untreated major dissection, characterized by an arc $>60^{\circ}$ or $3 \mathrm{~mm}$ in length, was less likely to be found in the OCT-guided PCI cohort compared with IVUS-guided cohort (45). Owing to its greater resolution, OCT enhances the ability to detect post-PCI complications such as major dissections and geographical miss, compared with IVUS.

\section{Intravascular imaging and stent under expansion}

A smaller post-PCI MSA (or stent under-expansion) is an independent predictor of poor outcomes, especially stent failure (thrombosis and restenosis) $(43,46,47)$. In the non-left main segments, the optimal MSA cutoff on IVUS for most drug-eluting stents ranges between 5.3 to $5.7 \mathrm{~mm}^{2}$ (48-50). Similarly, based on a large OCT registry of 786 patients, the MSA cutoff value of $5.0 \mathrm{~mm}^{2}$ for drug-eluting stents was an independent predictor of major adverse cardiac events and TLR (51). Another analysis of 832 patients demonstrated that MSA values $<4.5 \mathrm{~mm}^{2}$ on OCT were independently 
Table 2 IVUS stent optimization criteria

\begin{tabular}{|c|c|c|c|c|c|}
\hline TULIP criteria (31) & AVID criteria (32) & MUSIC criteria $(30,33)$ & RESIST criteria (34) & BEST criteria (35) & $\begin{array}{l}\text { AVIO criteria }(36), \\
\text { [balloon size }(\mathrm{mm}) / \\
\text { achievable optimal } \\
\left.\text { result }\left(\mathrm{mm}^{2}\right)\right]\end{array}$ \\
\hline $\begin{array}{l}\text { Complete stent } \\
\text { apposition }\end{array}$ & $\begin{array}{l}\text { MLA } \geq 90 \% \text { of } \\
\text { distal minimal } \\
\text { vessel lumen } \\
\text { CSA }\end{array}$ & Complete stent apposition & $\begin{array}{l}\text { IVUS criteria for } \\
\text { crossover to stent: } \\
>30 \% \text { stenosis or } \\
\text { MLA }<6 \mathrm{~mm}^{2}\end{array}$ & $\begin{array}{l}\text { Stent CSA }>80 \% \\
\text { of the mean } \\
\text { proximal and } \\
\text { distal reference } \\
\text { vessel CSA }\end{array}$ & $\begin{array}{c}2.25 / 3.5 ; 2.5 / 4 \\
3 / 6 ; 3.5 / 8 ; 4 / 10 \\
4.5 / 12\end{array}$ \\
\hline $\begin{array}{l}\text { MLD } \geq 80 \% \text { of } \\
\text { the mean of } \\
\text { proximal and } \\
\text { distal reference } \\
\text { diameters }\end{array}$ & $\begin{array}{l}\text { Complete stent } \\
\text { apposition }\end{array}$ & $\begin{array}{l}\text { MLA } \geq 90 \% \text { of the average } \\
\text { reference lumen area or } \geq 100 \% \\
\text { of the lumen area of the reference } \\
\text { segment with the lowest lumen } \\
\text { area. MLA }>9.0 \mathrm{~mm}^{2} . \mathrm{MLA} \geq 80 \% \\
\text { of the average reference lumen } \\
\text { area or } \geq 90 \% \text { of the lumen area } \\
\text { of the reference segment with the } \\
\text { lowest lumen area }\end{array}$ & & & \\
\hline $\begin{array}{l}\mathrm{MLA} \geq \text { distal } \\
\text { reference lumen } \\
\text { area }\end{array}$ & $\begin{array}{l}\text { Dissections } \\
\text { covered by the } \\
\text { stent }\end{array}$ & Symmetric stent expansion & & & \\
\hline
\end{tabular}

IVUS, intravascular ultrasound.

associated with major adverse cardiac events (43).

\section{Impact of intravascular imaging on clinical outcomes}

Meta-analyses of randomized trials and registry data have shown significant major adverse cardiovascular event (MACE) reductions with IVUS-guided PCI compared with conventional angiography-guided PCI (52-55). The IVUS-XPL trial (56) was a randomized study comparing IVUS-guided PCI with conventional angiography in 1,400 patients with lesions $\geq 28 \mathrm{~mm}$ in length that were treated with XIENCE (Abbott Vascular, Santa Clara, California) stents. At 5 years follow-up (56), MACE reductions were significant with a hazard ratio of 0.50 (95\% CI: 0.34-0.75) in the IVUS-guided PCI cohort compared with conventional angiography. This was mainly driven by lower rates of TLR. A recent meta-analysis of 5,532 patients from 11 clinical trials showed statistically significant reductions in cardiovascular mortality (OR: 0.45, 95\% CI: 0.25-0.80), TLR (OR: $0.56,95 \%$ CI: 0.41-0.77) and stent thrombosis (OR: 0.47, 95\% CI: 0.24-0.94) with IVUS-guided PCI compared with conventional angiography (52). In another meta-analysis, IVUS was particularly beneficial in complex coronary lesions such as left main disease, bifurcations, ACS and chronic total occlusions (CTO) (57). Figure 4 shows forest plots demonstrating cardiovascular mortality reduction in left main as well as non-left main lesions with IVUS-guided PCI in comparison with conventional angiography.

\section{IVUS and OCT: head to head comparison}

Bezerra et al. (12) assessed 100 frequency-domain OCT/ IVUS pull backs in stented $(\mathrm{n}=44)$, and native vessels $(\mathrm{n}=56)$. OCT depicted more severe native coronary disease compared with IVUS (MLA OCT $2.33 \pm 1.56 \mathrm{~mm}^{2}$ IVUS $\left.3.32 \pm 1.92 \mathrm{~mm}^{2}, \mathrm{P}<0.001\right)$. Reference vessel dimensions and post-PCI MSA were similar across the OCT and IVUS pull backs. OCT was better at detecting neointimal hyperplasia, post-PCI malapposition and tissue prolapse compared with IVUS. The OPUS-CLASS study (58) performed a core laboratory analysis of IVUS and OCT studies on 100 patients with coronary artery disease. The MLA was significantly larger on IVUS compared with OCT $(3.68 \pm 2.06$ vs. $\left.3.27 \pm 2.22 \mathrm{~mm}^{2}, \mathrm{P}<0.001\right)$. There was strong correlation $(\mathrm{r}=0.95, \mathrm{P}<0.001)$ observed among the two intravascular imaging modalities with good interobserver reproducibility. 


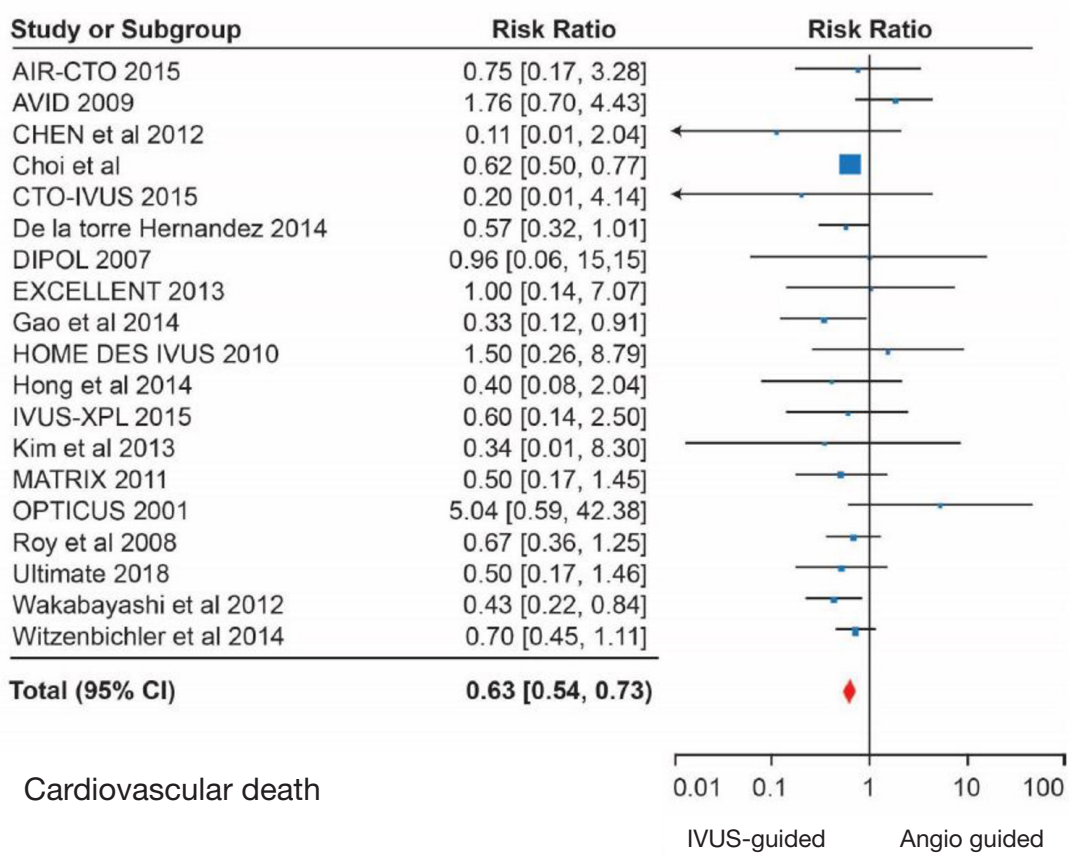

Figure 4 Forest plot demonstrating a reduction in cardiovascular death with IVUS PCI in contrast to conventional angiography in the left main and non-left main lesions. IVUS, intravascular ultrasound; PCI, percutaneous coronary intervention.

The ILUMIEN II study (59) assessed stent expansion across a 286 propensity-matched pairs (IVUS and OCT). Stent expansion was similar across the IVUS- and OCTguided PCI cohorts. OCT was better at detecting stent malapposition, tissue protrusion, and edge dissections compared with IVUS. Habara et al. (60) published a randomized clinical trial comparing OCT-guided PCI to IVUS-guided PCI in 70 patients with de novo coronary lesions. There were no differences in procedural time and contrast volume between IVUS- or OCT-guided PCI. The MSA attained post-PCI was significantly larger with IVUS compared with the OCT-treated group. This was likely driven by suboptimal visualization of the EEM with OCT resulting in angiographic-equivalent sizing of the vessel in $40 \%$ of the cases.

The OPINION trial (61) was a randomized study of 829 patients that compared OCT with IVUS-guided PCI. For those randomized to the OCT-guided PCI group, the distal reference lumen diameter was used whereas the IVUS-guided PCI cohort used the distal EEM measurement for stent selection and optimization. As a result, the IVUS-guided PCI arm had a significantly larger stent diameter compared with the OCT arm (2.99 vs. $2.92 \mathrm{~mm}, \mathrm{P}=0.005)$. The incidence of target vessel failure was not different among the two cohorts. ILUMIEN III (45) was a prospective multicenter non-inferiority trial that randomized 450 patients to IVUS-guided PCI, OCTguided PCI and conventional angiography-guided PCI. The primary efficacy endpoint was post-PCI MSA and the primary safety endpoint was peri-procedural MACE. This trial introduced a novel OCT criterion based on the EEM measurements. The EEM diameter of the distal vessel was used if the EEM circumference is visible beyond $180^{\circ}$ (rounded down by $0.25 \mathrm{~mm}$ to the closest stent platform size). If not, the mean distal vessel lumen diameter was used to select the appropriate stent. Coronary artery tapering was considered in the OCT stent optimization criteria, and the stented section was split into proximal and distal segments. Acute procedural success was classified into optimal and acceptable. Optimal stent expansion was defined as the "MSA of the proximal segment being $\geq 95 \%$ of the proximal reference lumen area, with the MSA of the distal segment being $\geq 95 \%$ of the distal reference lumen area" (45). Acceptable stent expansion was defined as the "MSA of the proximal segment being $\geq 90 \%$ of the proximal reference lumen area, and the MSA of the distal segment being $\geq 90 \%$ of the distal reference lumen area" (45). With these criteria, OCT was found to be non-inferior to IVUS 


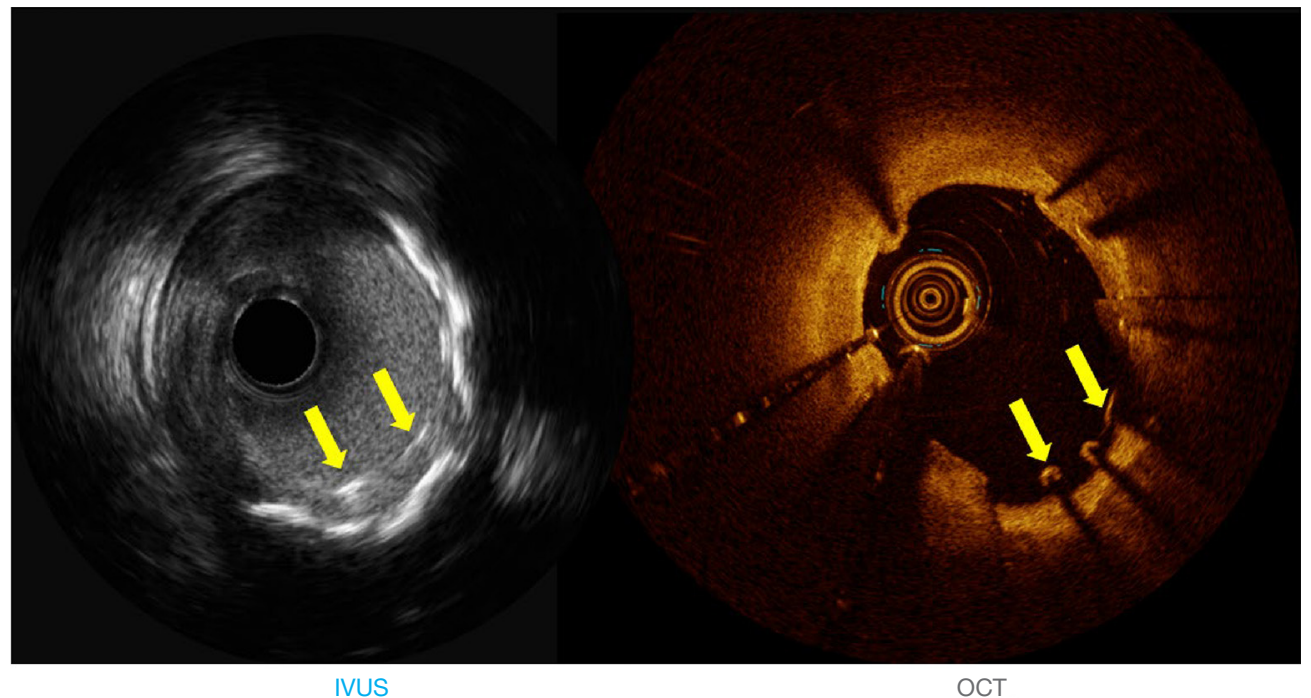

Figure 5 Malapposition of stent struts (yellow arrows) on IVUS and OCT courtesy Boston Scientific. IVUS, intravascular ultrasound; OCT, optical coherence tomography.

for the primary safety/efficacy endpoint. Major dissection and stent malapposition (Figure 5) were lower in the OCT arm compared with IVUS and conventional angiography.

Recently a small study of 29 patients (29 lesions) (62) performed $60-\mathrm{MHz}$ high definition IVUS and OCT before and after PCI. There was a greater correlation between high definition-IVUS and OCT concerning lumen area measurement before and after PCI. Pre-PCI, HD-IVUS was superior to OCT for EEM visualization, and OCT was superior in detecting plaque rupture or thrombus compared with HD-IVUS. Post PCI, OCT was better than HDIVUS in identifying tissue protrusion, stent edge dissection, and acute stent malapposition. The OCTIVUS trial (NCT03394079) is currently underway comparing OCT with IVUS-guided PCI. The primary endpoint of this trial is target vessel failure at 1 year.

\section{IVUS superior to OCT}

\section{Left main and ostial disease}

The European Society of Cardiology 2018 guidelines offer a Class IIa recommendation for IVUS assessment of indeterminate left main coronary artery (LMCA) lesions (63). A minimal lumen area (MLA) $<6 \mathrm{~mm}^{2}$ correlates with a fractional flow reserve of less than 0.75 $(64,65)$. Amongst Asians, this MLA cut-off appears lower at around $4.5-4.8 \mathrm{~mm}^{2}$ (66). It is essential to perform IVUS pullbacks across the LMCA bifurcation (both LAD and LCx branches) to accurately classify the distal left main bifurcation based on plaque distribution (67). Identifying susceptible carina and substantial ostial calcification is crucial to prevent side branch loss $(68,69)$. An appropriate bifurcation stent strategy should then be undertaken based upon plaque distribution. The LMCA ostium can be marked by IVUS and can be imaged in a coaxial fashion with guide catheter disengagement. This holds good for any aortoostial lesion. OCT is suboptimal for adequate visualization of aorto-ostial lesions due to inadequate blood clearance. Iatrogenic aortocoronary ostial dissections are uncommon but a fatal complication of coronary angiography (70). Following an iatrogenic coronary artery dissection, contrast injections should be avoided and IVUS should be performed to confirm the distal wire position in the true lumen as well as the extent of the dissection (71-73). Video 2 is an IVUS pullback that confirms the wire position in the false lumen.

A randomized trial (74) of over 300 patients demonstrated a substantial reduction in cardiac mortality with IVUSguided LMCA PCI when compared with conventional angiography. Subsequently, a meta-analysis (75) of nearly 4,500 patients showed that IVUS-guided LMCA PCI was superior to conventional angiography with a significant reduction in major adverse cardiac events, all-cause mortality, cardiac mortality, myocardial infarction, and stent thrombosis. A Swedish Registry (76) of over 2,400 patients with $25 \%$ IVUS use confirmed IVUS-guided LMCA PCI 
was associated with a considerable MACE reduction at 10 years (HR: 0.65, 95\% CI: 0.50-0.84) compared with conventional angiography. In Asians, in-stent restenosis rates are lower if the minimal stent area (MSA) post LMCA PCI is more than $5.0 \mathrm{~mm}^{2}$ (for the ostial left circumflex), 6.0 $\mathrm{mm}^{2}$ (ostial left anterior descending), $>7.0 \mathrm{~mm}^{2}$ (polygonal of confluence), and $>8.0 \mathrm{~mm}^{2}$ (left main body) (48). For nonAsians it would be reasonable to add $0.5 \mathrm{~mm}$ to these cutoffs. There is currently no literature supporting the use of OCT in LMCA disease. The ILUMIEN III: OPTIMIZE PCI trial (45) excluded left main or ostial right coronary artery stenosis, highlighting the limitation of OCT.

\section{CTO and complex disease}

IVUS has established itself in the realm of CTO PCI. IVUS has been used as an adjunct tool to cross an ambiguous cap or flush occlusion of a large epicardial vessel. IVUS confirms the wire position after successful entry. In addition, IVUS can assess plaque morphology, burden and appropriate landing zones (77). IVUS-guided cap puncture and redirection during antegrade wire escalation and dissection reentry, respectively cannot be replaced by OCT. IVUS also identifies the appropriate balloon size and a calcium-free zone to perform reverse controlled antegrade and retrograde tracking (78). Lastly, there is evidence to suggest that IVUS-guided CTO intervention is associated with lower rates of stent thrombosis, myocardial infarction, and TLR when compared with conventional angiography $(79,80)$.

Similarly, IVUS has also been proven to be beneficial in optimizing outcomes in bifurcations and complex coronary lesions (81). On the other hand, the role of OCT is currently being studied to assess stent apposition/complex histopathological remodeling after CTO PCI $(82,83)$, as well as for optimizing bifurcation stenting $(84,85)$. Multiple Japanese studies have been published so far that have utilized OCT to meticulously find and prove distal stent strut passage of guidewire during bifurcation stenting for optimal strut configuration (86-89). This technique is promising and helps to achieve symmetric stent expansion; however, in practice it is time-consuming requiring multiple runs of OCT increasing contrast administration (85).

\section{Renal dysfunction}

Contrast-induced nephropathy after PCI is a poor prognostic factor and often delays discharge resulting in greater resource utilization and hospitalization costs (90). IVUS is a contrast- sparing modality and is particularly useful in advanced chronic kidney disease (91-93) and valuable in the context of contrast allergy (94). IVUS-guided minimum-contrast PCI significantly lowers contrast use, risk of contrast-induced nephropathy, and the need for dialysis $(91,92,95,96)$. Residual kidney function in patients on dialysis is linked to better survival and quality life, supporting the benefit of IVUS over OCT in this high-risk population for PCI optimization (97). Patients with end-stage renal failure harbor often heavily calcified plaque and thus require plaque modification (i.e., rotational atherectomy) (19). Zero-contrast PCI in calcified lesions facilitated by rotational atherectomy can be safely accomplished in this group (98). The use of dextran instead of contrast to perform OCT $(11,99)$ has been reported in the literature to prevent contrast-induced acute kidney injury.

\section{Advantages of OCT}

\section{Stent failure}

Intravascular imaging plays a crucial role in understanding the mechanism of stent failure. Stent under-expansion is a major cause of stent failure $(100,101)$. Neointimal calcification is found in circa $20 \%$ of the cases with in-stent restenosis and owing to its greater imaging resolution, OCT is generally superior in visualizing these changes compared with IVUS. An OCT registry consisting of $40 \%$ bare-metal stents and $60 \%$ drug-eluting stents accurately defined the mechanism of 23 definite stent thromboses and 97 late or very late stent thromboses (102). Definite stent thrombosis was attributed to stent malapposition (48\%), severe stent under-expansion (26\%), and distal edge dissection (8\%). These findings were similar to previously published IVUS data (41). Late or very late stent thrombosis etiologies include stent malapposition (Figure 5) (32\%), ruptured neoatherosclerosis $(28 \%)$, evagination $(10 \%)$, uncovered stent struts (10\%), stent edge-related disease progression $(8 \%)$, and severe stent under-expansion (7\%). Tissue protrusion is a common phenomenon following stenting; more likely to occur in patients presenting with an ACS. Tissue protrusion indicates larger stent expansion when seen on IVUS. It is typically not associated with worse outcomes unless there is lumen compromise that could lead to stent thrombosis $(41,103)$. On OCT, asymmetrical tissue protrusion has been linked to target vessel failure (51).

Acute stent malapposition is twice more likely to be detected on OCT compared with IVUS (58). Malapposed stents, irrespective of the degree and despite adequate 

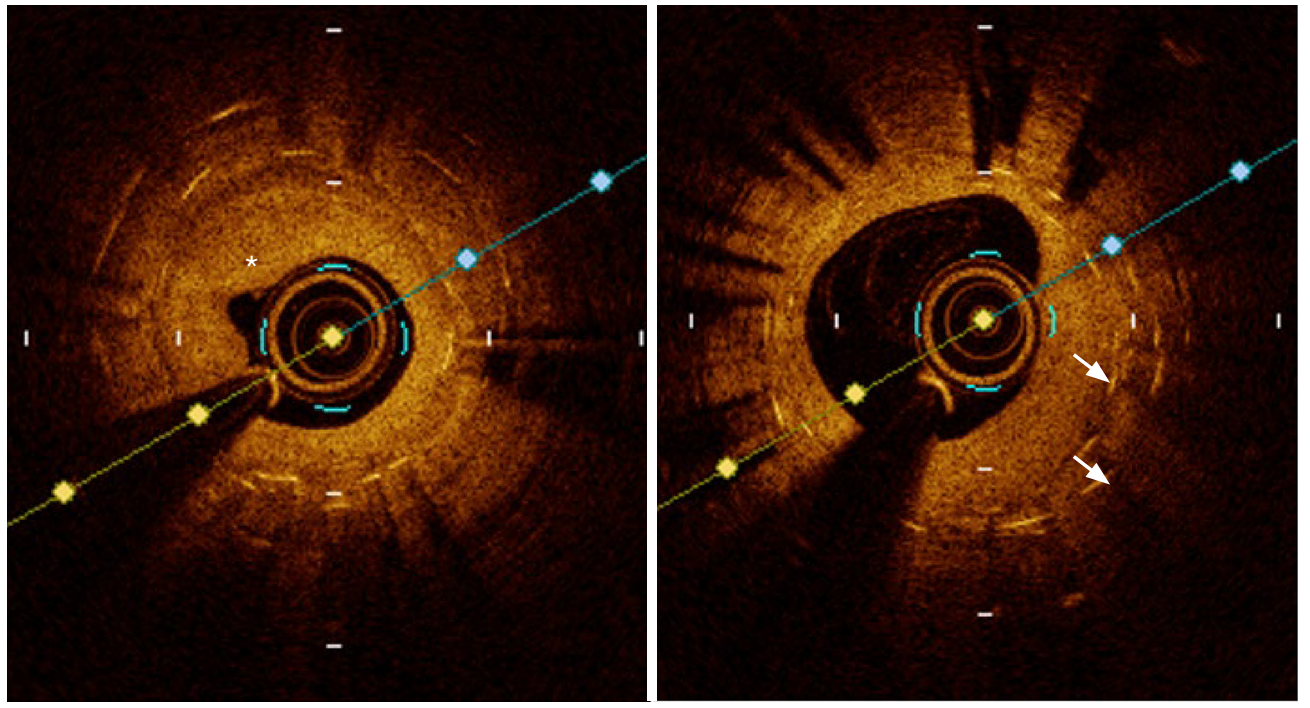

Figure 6 OCT images showing multiple stent layers (white arrows) with severe in-stent restenosis and neointimal hyperplasia (asterisk). OCT, optical coherence tomography.

stent expansion, are associated with worse short- and longterm outcomes $(41,43,51,104,105)$. Late-acquired stent malapposition is a phenomenon attributed to positive vessel remodeling with or without thrombus resolution. Very late stent thrombosis has been linked to late-acquired stent malapposition (106). As IVUS can evaluate the vessel wall in its entirety, it is commonly the preferred modality for detecting late-acquired stent malapposition. On the other hand, OCT is superior to IVUS for detecting neoatherosclerosis, and incomplete tissue coverage/ uncovered stent struts $(102,107)$. Intravascular imaging with OCT (108) helped to ascertain the cause of stent thrombosis in over $30 \%$ more cases compared with conventional angiography alone. Figure 6 demonstrates multiple layers of stent on OCT with severe in-stent restenosis and neointimal hyperplasia.

\section{Diagnostic dilemmas}

Myocardial infarction with non-obstructive coronary arteries (MINOCA) is a common clinical presentation and often perplexing (109). No clear etiology is often identified for MINOCA; however, this entity carries a 1-year mortality rate of nearly $5 \%$ (110). OCT helps to exclude thin-cap fibroatheroma/plaque rupture and thrombus or spontaneous coronary artery dissection (SCAD) as potential substrates for MINOCA (111). In a prospective study of 38 MINOCA patients, OCT and cardiac magnetic resonance imaging were performed to identify the infarct-related artery (111). The mean age of the cohort was 62 years consisting predominantly of women $(55 \%)$, and over onethird of them presented with ST-segment elevation. Plaque disruption and thrombus was present in $42 \%$ of the patients and could be linked to the location of the ischemic-type myocardial injury on cardiac magnetic resonance imaging.

\section{Safety and cost-effectiveness}

The incidence of complications in a large series of intravascular imaging-guided procedures $(1,142$ OCT and 2,476 IVUS procedures) (112) was around $0.5 \%$. This included transient ST-elevation (OCT $=0.26 \%$ and IVUS $=0.08 \%)$, bradycardia (OCT $=0.18 \%$ and IVUS $=0.04 \%$ ), coronary spasm (OCT $=0.09 \%$ and IVUS $=0.04 \%$ ), thrombus formation $(\mathrm{OCT}=0.09 \%$ and IVUS $=0.16 \%$ ), dissection (OCT $=0 \%$ and IVUS $=0.12 \%)$, and stent deformation (OCT $=0 \%$ and IVUS $=0.04 \%$ ). Most of these complications were self-limiting following imaging catheter removal. There were no IVUS or OCT-related mortalities (112). IVUS is a cost-effective strategy $(54,113)$ at one year. This economic impact is even greater in individuals with renal dysfunction, diabetes, and ACS. The health-economic impact continues to be seen with the use of second-generation drug-eluting stents at 1 - and 2-year post PCI $(6,114)$. The 5 -year results of the IVUS-XPL trial (56) further support the health-economic impact of IVUS. 


\section{Conclusions}

Intravascular imaging plays an important role in contemporary PCI for optimizing stent and patient-oriented outcomes. IVUS and OCT are based on differing imaging principles, yet each harbor unique advantages according to the specific clinical situation at hand. IVUS is superior in the diagnosis and management of patients with LMCA disease, renal dysfunction, aorto-coronary ostial lesions, and CTO. The visualization of the EEM with IVUS enables one to acquire a larger MSA compared with OCT. OCT is a relatively newer technology with superior image resolution to IVUS, with an emerging evidence-base outlining its use. OCT is superior to IVUS in assessing the etiology of stent failure, calcific coronary disease, and MINOCA. Ultimately, the relevant intravascular imaging modality should be chosen appropriately to cater to the needs of the specific patient during cardiac catheterization, based upon the clinical context and comorbidities.

\section{Acknowledgments}

Funding: None.

\section{Footnote}

Provenance and Peer Review: This article was commissioned by the Guest Editor (Dennis T. L. Wong) for the series "Intracoronary Imaging" published in Cardiovascular Diagnosis and Therapy. The article was sent for external peer review organized by the Guest Editor and the editorial office.

Conflicts of Interest: All authors have completed the ICMJE uniform disclosure forms (available at http://dx.doi. org/10.21037/cdt-20-206). The series "Intracoronary Imaging" was commissioned by the editorial office without any funding or sponsorship. The authors have no other conflicts of interest to declare.

Ethical Statement: The authors are accountable for all aspects of the work in ensuring that questions related to the accuracy or integrity of any part of the work are appropriately investigated and resolved.

Open Access Statement: This is an Open Access article distributed in accordance with the Creative Commons Attribution-NonCommercial-NoDerivs 4.0 International License (CC BY-NC-ND 4.0), which permits the non- commercial replication and distribution of the article with the strict proviso that no changes or edits are made and the original work is properly cited (including links to both the formal publication through the relevant DOI and the license). See: https://creativecommons.org/licenses/by-nc-nd/4.0/.

\section{References}

1. Bruch L, Zadura M, Waliszewski M, et al. Results From the International Drug Coated Balloon Registry for the Treatment of Bifurcations. Can a Bifurcation Be Treated Without Stents? J Interv Cardiol 2016;29:348-56.

2. Kobayashi N, Mintz GS, Witzenbichler B, et al. Prevalence, Features, and Prognostic Importance of Edge Dissection After Drug-Eluting Stent Implantation: An ADAPT-DES Intravascular Ultrasound Substudy. Circ Cardiovasc Interv 2016;9:e003553.

3. Hoffmann R, Mintz GS, Popma JJ, et al. Treatment of calcified coronary lesions with Palmaz-Schatz stents. An intravascular ultrasound study. Eur Heart J 1998;19:1224-31.

4. Lee MS, Shlofmitz E, Kong J, et al. Impact of the Use of Intravascular Imaging on Patients Who Underwent Orbital Atherectomy. J Invasive Cardiol 2018;30:77-80.

5. Chieffo A, Latib A, Caussin C, et al. A prospective, randomized trial of intravascular-ultrasound guided compared to angiography guided stent implantation in complex coronary lesions: the AVIO trial. Am Heart J 2013;165:65-72.

6. Witzenbichler B, Maehara A, Weisz G, et al. Relationship between intravascular ultrasound guidance and clinical outcomes after drug-eluting stents: the assessment of dual antiplatelet therapy with drug-eluting stents (ADAPTDES) study. Circulation 2014;129:463-70.

7. Buccheri S, Franchina G, Romano S, et al. Clinical Outcomes Following Intravascular Imaging-Guided Versus Coronary Angiography-Guided Percutaneous Coronary Intervention With Stent Implantation: A Systematic Review and Bayesian Network Meta-Analysis of 31 Studies and 17,882 Patients. JACC Cardiovasc Interv 2017;10:2488-98.

8. Tearney GJ, Regar E, Akasaka T, et al. Consensus standards for acquisition, measurement, and reporting of intravascular optical coherence tomography studies: a report from the International Working Group for Intravascular Optical Coherence Tomography 
Standardization and Validation. J Am Coll Cardiol 2012;59:1058-72.

9. Di Vito L, Yoon JH, Kato K, et al. Comprehensive overview of definitions for optical coherence tomographybased plaque and stent analyses. Coron Artery Dis 2014;25:172-85.

10. Mintz GS, Nissen SE, Anderson WD, et al. American College of Cardiology Clinical Expert Consensus Document on Standards for Acquisition, Measurement and Reporting of Intravascular Ultrasound Studies (IVUS). A report of the American College of Cardiology Task Force on Clinical Expert Consensus Documents. J Am Coll Cardiol 2001;37:1478-92.

11. Azzalini L, Mitomo S, Hachinohe D, et al. Zero-Contrast Percutaneous Coronary Intervention Guided by DextranBased Optical Coherence Tomography. Can J Cardiol 2018;34:342.e1-342.e3.

12. Bezerra HG, Attizzani GF, Sirbu V, et al. Optical coherence tomography versus intravascular ultrasound to evaluate coronary artery disease and percutaneous coronary intervention. JACC Cardiovasc Interv 2013;6:228-36.

13. Gerbaud E, Weisz G, Tanaka A, et al. Multi-laboratory inter-institute reproducibility study of IVOCT and IVUS assessments using published consensus document definitions. Eur Heart J Cardiovasc Imaging 2016;17:756-64.

14. Mintz GS, Popma JJ, Pichard AD, et al. Patterns of calcification in coronary artery disease. A statistical analysis of intravascular ultrasound and coronary angiography in 1155 lesions. Circulation 1995;91:1959-65.

15. Kostamaa H, Donovan J, Kasaoka S, et al. Calcified plaque cross-sectional area in human arteries: correlation between intravascular ultrasound and undecalcified histology. Am Heart J 1999;137:482-8.

16. Friedrich GJ, Moes NY, Mühlberger VA, et al.

Detection of intralesional calcium by intracoronary ultrasound depends on the histologic pattern. Am Heart J 1994;128:435-41.

17. Kobayashi Y, Okura H, Kume T, et al. Impact of Target Lesion Coronary Calcification on Stent Expansion. Circ J 2014;78:2209-14.

18. Kobayashi N, Ito Y, Yamawaki M, et al. Clinical efficacy of optical coherence tomography-guided versus intravascular ultrasound-guided rotational atherectomy for calcified coronary lesion. EuroIntervention 2019. [Epub ahead of print].
19. De Maria GL, Scarsini R, Banning AP. Management of Calcific Coronary Artery Lesions. JACC Cardiovasc Interv 2019;12:1465-78.

20. Aksoy A, Salazar C, Becher MU, et al. Intravascular Lithotripsy in Calcified Coronary Lesions: A Prospective, Observational, Multicenter Registry. Circ Cardiovasc Interv 2019;12:e008154.

21. Ali ZA, Brinton TJ, Hill JM, et al. Optical Coherence Tomography Characterization of Coronary Lithoplasty for Treatment of Calcified Lesions: First Description. JACC Cardiovasc Imaging 2017;10:897-906.

22. Wong B, El-Jack S, Newcombe R, et al. Shockwave Intravascular Lithotripsy for Calcified Coronary Lesions: First Real-World Experience. J Invasive Cardiol 2019;31:46-8.

23. Patel VG, Brayton KM, Mintz GS, et al. Intracoronary and noninvasive imaging for prediction of distal embolization and periprocedural myocardial infarction during native coronary artery percutaneous intervention. Circ Cardiovasc Imaging 2013;6:1102-14.

24. Kimura S, Kakuta T, Yonetsu T, et al. Clinical significance of echo signal attenuation on intravascular ultrasound in patients with coronary artery disease. Circ Cardiovasc Interv 2009;2:444-54.

25. Endo M, Hibi K, Shimizu T, et al. Impact of ultrasound attenuation and plaque rupture as detected by intravascular ultrasound on the incidence of no-reflow phenomenon after percutaneous coronary intervention in ST-segment elevation myocardial infarction. JACC Cardiovasc Interv 2010;3:540-9.

26. Ali ZA, Roleder T, Narula J, et al. Increased thin-cap neoatheroma and periprocedural myocardial infarction in drug-eluting stent restenosis: multimodality intravascular imaging of drug-eluting and bare-metal stents. Circ Cardiovasc Interv 2013;6:507-17.

27. Pu J, Mintz GS, Biro S, et al. Insights into echo-attenuated plaques, echolucent plaques, and plaques with spotty calcification: novel findings from comparisons among intravascular ultrasound, near-infrared spectroscopy, and pathological histology in 2,294 human coronary artery segments. J Am Coll Cardiol 2014;63:2220-33.

28. Mangiacapra F, Peace AJ, Di Serafino L, et al. Intracoronary EnalaPrilat to Reduce MICROvascular Damage During Percutaneous Coronary Intervention (ProMicro) study. J Am Coll Cardiol 2013;61:615-21. 29. Hibi K, Kozuma K, Sonoda S, et al. A Randomized Study 
of Distal Filter Protection Versus Conventional Treatment During Percutaneous Coronary Intervention in Patients With Attenuated Plaque Identified by Intravascular Ultrasound. JACC Cardiovasc Interv 2018;11:1545-55.

30. de Jaegere P, Mudra H, Figulla H, et al. Intravascular ultrasound-guided optimized stent deployment. Immediate and 6 months clinical and angiographic results from the Multicenter Ultrasound Stenting in Coronaries Study (MUSIC Study). Eur Heart J 1998;19:1214-23.

31. Oemrawsingh PV, Mintz GS, Schalij MJ, et al. Intravascular ultrasound guidance improves angiographic and clinical outcome of stent implantation for long coronary artery stenoses: final results of a randomized comparison with angiographic guidance (TULIP Study). Circulation 2003;107:62-7.

32. Russo RJ, Silva PD, Teirstein PS, et al. A randomized controlled trial of angiography versus intravascular ultrasound-directed bare-metal coronary stent placement (the AVID Trial). Circ Cardiovasc Interv 2009;2:113-23.

33. Frey AW, Hodgson JM, Muller C, et al. Ultrasoundguided strategy for provisional stenting with focal balloon combination catheter: results from the randomized Strategy for Intracoronary Ultrasound-guided PTCA and Stenting (SIPS) trial. Circulation 2000;102:2497-502.

34. Schiele F, Meneveau N, Vuillemenot A, et al. Impact of intravascular ultrasound guidance in stent deployment on 6-month restenosis rate: a multicenter, randomized study comparing two strategies--with and without intravascular ultrasound guidance. RESIST Study Group. REStenosis after Ivus guided STenting. J Am Coll Cardiol 1998;32:320-8.

35. Schiele F, Meneveau N, Gilard M, et al. Intravascular ultrasound-guided balloon angioplasty compared with stent: immediate and 6-month results of the multicenter, randomized Balloon Equivalent to Stent Study (BEST). Circulation 2003;107:545-51.

36. Johnson TW, Raber L, di Mario C, et al. Clinical use of intracoronary imaging. Part 2: acute coronary syndromes, ambiguous coronary angiography findings, and guiding interventional decision-making: an expert consensus document of the European Association of Percutaneous Cardiovascular Interventions. Eur Heart J 2019;40:2566-84.

37. Mintz GS, Painter JA, Pichard AD, et al. Atherosclerosis in angiographically "normal" coronary artery reference segments: an intravascular ultrasound study with clinical correlations. J Am Coll Cardiol 1995;25:1479-85.

38. Costa MA, Angiolillo DJ, Tannenbaum M, et al. Impact of stent deployment procedural factors on long-term effectiveness and safety of sirolimus-eluting stents (final results of the multicenter prospective STLLR trial). Am J Cardiol 2008;101:1704-11.

39. Liu J, Maehara A, Mintz GS, et al. An integrated TAXUS $\mathrm{IV}, \mathrm{V}$, and VI intravascular ultrasound analysis of the predictors of edge restenosis after bare metal or paclitaxeleluting stents. Am J Cardiol 2009;103:501-6.

40. Fujii K, Carlier SG, Mintz GS, et al. Stent underexpansion and residual reference segment stenosis are related to stent thrombosis after sirolimus-eluting stent implantation: an intravascular ultrasound study. J Am Coll Cardiol 2005;45:995-8.

41. Choi SY, Witzenbichler B, Maehara A, et al. Intravascular ultrasound findings of early stent thrombosis after primary percutaneous intervention in acute myocardial infarction: a Harmonizing Outcomes with Revascularization and Stents in Acute Myocardial Infarction (HORIZONS-AMI) substudy. Circ Cardiovasc Interv 2011;4:239-47.

42. Kang SJ, Cho YR, Park GM, et al. Intravascular ultrasound predictors for edge restenosis after newer generation drug-eluting stent implantation. Am J Cardiol 2013;111:1408-14.

43. Prati F, Romagnoli E, Burzotta F, et al. Clinical Impact of OCT Findings During PCI: The CLI-OPCI II Study. JACC Cardiovasc Imaging 2015;8:1297-305.

44. Ino Y, Kubo T, Matsuo Y, et al. Optical Coherence Tomography Predictors for Edge Restenosis After Everolimus-Eluting Stent Implantation. Circ Cardiovasc Interv 2016;9:e004231.

45. Ali ZA, Maehara A, Généreux P, et al. Optical coherence tomography compared with intravascular ultrasound and with angiography to guide coronary stent implantation (ILUMIEN III: OPTIMIZE PCI): a randomised controlled trial. Lancet 2016;388:2618-28.

46. Moussa I, Moses J, Di Mario C, et al. Does the specific intravascular ultrasound criterion used to optimize stent expansion have an impact on the probability of stent restenosis? Am J Cardiol 1999;83:1012-7.

47. Liu X, Doi H, Maehara A, et al. A volumetric intravascular ultrasound comparison of early drug-eluting stent thrombosis versus restenosis. JACC Cardiovasc Interv 2009;2:428-34.

48. Kang SJ, Ahn JM, Song H, et al. Comprehensive intravascular ultrasound assessment of stent area and its impact on restenosis and adverse cardiac events in 403 patients with unprotected left main disease. Circ Cardiovasc Interv 2011;4:562-9. 
49. Doi H, Maehara A, Mintz GS, et al. Impact of postintervention minimal stent area on 9-month followup patency of paclitaxel-eluting stents: an integrated intravascular ultrasound analysis from the TAXUS IV, V, and VI and TAXUS ATLAS Workhorse, Long Lesion, and Direct Stent Trials. JACC Cardiovasc Interv 2009;2:1269-75.

50. Song HG, Kang SJ, Ahn JM, et al. Intravascular ultrasound assessment of optimal stent area to prevent in-stent restenosis after zotarolimus-, everolimus-, and sirolimuseluting stent implantation. Catheter Cardiovasc Interv 2014;83:873-8.

51. Soeda T, Uemura S, Park SJ, et al. Incidence and Clinical Significance of Poststent Optical Coherence Tomography Findings: One-Year Follow-Up Study From a Multicenter Registry. Circulation 2015;132:1020-9.

52. Kumar A, Shariff M, Adalja D, et al. Intravascular ultrasound versus angiogram guided drug eluting stent implantation. A systematic review and updated metaanalysis with trial sequential analysis. Int J Cardiol Heart Vasc 2019;25:100419.

53. Zhang Y, Farooq V, Garcia-Garcia HM, et al. Comparison of intravascular ultrasound versus angiography-guided drug-eluting stent implantation: a meta-analysis of one randomised trial and ten observational studies involving 19,619 patients. EuroIntervention 2012;8:855-65.

54. Ahn JM, Kang SJ, Yoon SH, et al. Meta-analysis of outcomes after intravascular ultrasound-guided versus angiography-guided drug-eluting stent implantation in 26,503 patients enrolled in three randomized trials and 14 observational studies. Am J Cardiol 2014;113:1338-47.

55. Elgendy IY, Mahmoud AN, Elgendy AY, et al. Outcomes With Intravascular Ultrasound-Guided Stent Implantation: A Meta-Analysis of Randomized Trials in the Era of DrugEluting Stents. Circ Cardiovasc Interv 2016;9:e003700.

56. Hong SJ, Mintz GS, Ahn CM, et al. Effect of Intravascular Ultrasound-Guided Drug-Eluting Stent Implantation: 5-Year Follow-Up of the IVUS-XPL Randomized Trial. JACC Cardiovasc Interv 2020;13:62-71.

57. de la Torre Hernandez JM, Baz Alonso JA, Gómez Hospital JA, et al. Clinical impact of intravascular ultrasound guidance in drug-eluting stent implantation for unprotected left main coronary disease: pooled analysis at the patient-level of 4 registries. JACC Cardiovasc Interv 2014;7:244-54.

58. Kubo T, Akasaka T, Shite J, et al. OCT compared with IVUS in a coronary lesion assessment: the OPUS-CLASS study. JACC Cardiovasc Imaging 2013;6:1095-104.
59. Maehara A, Ben-Yehuda O, Ali Z, et al. Comparison of Stent Expansion Guided by Optical Coherence Tomography Versus Intravascular Ultrasound: The ILUMIEN II Study (Observational Study of Optical Coherence Tomography [OCT] in Patients Undergoing Fractional Flow Reserve [FFR] and Percutaneous Coronary Intervention). JACC Cardiovasc Interv 2015;8:1704-14.

60. Habara $M$, Nasu K, Terashima $M$, et al. Impact of frequency-domain optical coherence tomography guidance for optimal coronary stent implantation in comparison with intravascular ultrasound guidance. Circ Cardiovasc Interv 2012;5:193-201.

61. Kubo T, Shinke T, Okamura T, et al. Optical frequency domain imaging vs. intravascular ultrasound in percutaneous coronary intervention (OPINION trial): one-year angiographic and clinical results. Eur Heart J 2017;38:3139-47.

62. Garcia-Guimaraes M, Antuña P, De la Cuerda F, et al. High-Definition IVUS Versus OCT to Assess Coronary Artery Disease and Results of Stent Implantation. JACC Cardiovasc Imaging 2020;13:519-21.

63. Neumann F-J, Sousa-Uva M, Ahlsson A, et al. 2018 ESC/ EACTS Guidelines on myocardial revascularization. European Heart Journal 2019;40:87-165.

64. de la Torre Hernandez JM, Hernandez Hernandez F, Alfonso F, et al. Prospective application of pre-defined intravascular ultrasound criteria for assessment of intermediate left main coronary artery lesions results from the multicenter LITRO study. J Am Coll Cardiol 2011;58:351-8.

65. Jasti V, Ivan E, Yalamanchili V, et al. Correlations between fractional flow reserve and intravascular ultrasound in patients with an ambiguous left main coronary artery stenosis. Circulation 2004;110:2831-6.

66. Rusinova RP, Mintz GS, Choi SY, et al. Intravascular ultrasound comparison of left main coronary artery disease between white and Asian patients. Am J Cardiol 2013;111:979-84.

67. Oviedo C, Maehara A, Mintz GS, et al. Intravascular ultrasound classification of plaque distribution in left main coronary artery bifurcations: where is the plaque really located? Circ Cardiovasc Interv 2010;3:105-12.

68. Sato K, Naganuma T, Costopoulos C, et al. Calcification analysis by intravascular ultrasound to define a predictor of left circumflex narrowing after cross-over stenting for unprotected left main bifurcation lesions. Cardiovasc Revasc Med 2014;15:80-5.

69. Medina A, Martin P, Suarez de Lezo J, et al. Vulnerable 
carina anatomy and ostial lesions in the left anterior descending coronary artery after floating-stent treatment. Rev Esp Cardiol 2009;62:1240-9.

70. Hiraide T, Sawano M, Shiraishi Y, et al. Impact of catheter-induced iatrogenic coronary artery dissection with or without postprocedural flow impairment: A report from a Japanese multicenter percutaneous coronary intervention registry. PLoS One 2018;13:e0204333.

71. Cheng C-I, Wu C-J, Hsieh Y-K, et al. Percutaneous coronary intervention for iatrogenic left main coronary artery dissection. International Journal of Cardiology 2008;126:177-82.

72. Eshtehardi P, Adorjan P, Togni M, et al. Iatrogenic left main coronary artery dissection: incidence, classification, management, and long-term follow-up. Am Heart J 2010;159:1147-53.

73. Kuriyama N, Kobayashi Y, Shibata Y. Intravascular ultrasound-guided bailout for left main dissection. J Cardiol Cases 2012;5:e137-e9.

74. Liu XM, Yang ZM, Liu XK, et al. Intravascular ultrasoundguided drug-eluting stent implantation for patients with unprotected left main coronary artery lesions: A singlecenter randomized trial. Anatol J Cardiol 2019;21:83-90.

75. Wang Y, Mintz GS, Gu Z, et al. Meta-analysis and systematic review of intravascular ultrasound versus angiography-guided drug eluting stent implantation in left main coronary disease in 4592 patients. BMC Cardiovasc Disord 2018;18:115.

76. Andell P, Karlsson S, Mohammad MA, et al. Intravascular Ultrasound Guidance Is Associated With Better Outcome in Patients Undergoing Unprotected Left Main Coronary Artery Stenting Compared With Angiography Guidance Alone. Circ Cardiovasc Interv 2017;10:004813.

77. Ryan N, Gonzalo N, Dingli P, et al. Intravascular ultrasound guidance of percutaneous coronary intervention in ostial chronic total occlusions: a description of the technique and procedural results. Int J Cardiovasc Imaging 2017;33:807-13.

78. Dai J, Katoh O, Kyo E, et al. Approach for chronic total occlusion with intravascular ultrasound-guided reverse controlled antegrade and retrograde tracking technique: single center experience. J Interv Cardiol 2013;26:434-43.

79. Kim BK, Shin DH, Hong MK, et al. Clinical Impact of Intravascular Ultrasound-Guided Chronic Total Occlusion Intervention With Zotarolimus-Eluting Versus BiolimusEluting Stent Implantation: Randomized Study. Circ Cardiovasc Interv 2015;8:002592.

80. Hong SJ, Kim BK, Shin DH, et al. Usefulness of intravascular ultrasound guidance in percutaneous coronary intervention with second-generation drug-eluting stents for chronic total occlusions (from the Multicenter Korean-Chronic Total Occlusion Registry). Am J Cardiol 2014;114:534-40.

81. Patel Y, Depta JP, Novak E, et al. Long-term outcomes with use of intravascular ultrasound for the treatment of coronary bifurcation lesions. Am J Cardiol 2012;109:960-5.

82. Levesque S, Gamet A, Lattuca B, et al. Post-stEnting assessment of Reendothelialization with optical Frequency domain imaging aftEr Chronic Total Occlusion procedure: the PERFE-CTO study design and rationale. Cardiovasc Revasc Med 2020;21:760-4.

83. Xhepa E, Cassese S, Rroku A, et al. Subintimal Versus Intraplaque Recanalization of Coronary Chronic Total Occlusions: Mid-Term Angiographic and OCT Findings From the ISAR-OCT-CTO Registry. JACC Cardiovasc Interv 2019;12:1889-98.

84. Holm NR, Andreasen LN, Walsh S, et al. Rational and design of the European randomized Optical Coherence Tomography Optimized Bifurcation Event Reduction Trial (OCTOBER). Am Heart J 2018;205:97-109.

85. Shlofmitz E, Sosa F, Goldberg A, et al. Bifurcation and ostial optical coherence tomography mapping (BOOM) - Case description of a novel bifurcation stent technique. Cardiovasc Revasc Med 2018;19:47-9.

86. Nagoshi R, Okamura T, Murasato Y, et al. Feasibility and usefulness of three-dimensional optical coherence tomography guidance for optimal side branch treatment in coronary bifurcation stenting. Int J Cardiol 2018;250:270-4.

87. Okamura T, Onuma Y, Garcia-Garcia HM, et al. 3-Dimensional optical coherence tomography assessment of jailed side branches by bioresorbable vascular scaffolds: a proposal for classification. JACC Cardiovasc Interv 2010;3:836-44.

88. Okamura T, Onuma Y, Yamada J, et al. 3D optical coherence tomography: new insights into the process of optimal rewiring of side branches during bifurcational stenting. EuroIntervention 2014;10:907-15.

89. Fujimura T, Okamura T, Furuya K, et al. Comparison of diagnostic performance in assessing the rewiring position into a jailed side branch between online $3 \mathrm{D}$ reconstruction systems version 1.1 and 1.2 derived from optical frequency domain imaging. Cardiovasc Interv Ther 2020;35:336-42.

90. Wichmann Julian L, Katzberg Richard W, Litwin Sheldon E, et al. Contrast-Induced Nephropathy. Circulation 
2015;132:1931-6.

91. Sakai K, Ikari $Y$, Nanasato $M$, et al. Impact of intravascular ultrasound-guided minimum-contrast coronary intervention on 1-year clinical outcomes in patients with stage 4 or 5 advanced chronic kidney disease. Cardiovasc Interv Ther 2019;34:234-41.

92. Mariani J, Jr., Guedes C, Soares P, et al. Intravascular ultrasound guidance to minimize the use of iodine contrast in percutaneous coronary intervention: the MOZART (Minimizing cOntrast utiliZation With IVUS Guidance in coRonary angioplasTy) randomized controlled trial. JACC Cardiovasc Interv 2014;7:1287-93.

93. Nayak KR, Mehta HS, Price MJ, et al. A novel technique for ultra-low contrast administration during angiography or intervention. Catheter Cardiovasc Interv 2010;75:1076-83.

94. Nagaoka M, Tsumuraya N, Nie M, et al. Zero Contrast Coronary Intervention Using Intravascular Ultrasound Guidance in a Patient with Allergy to Contrast Medium. Tokai J Exp Clin Med 2016;41:152-5.

95. Ali ZA, Karimi Galougahi K, Nazif T, et al. Imaging- and physiology-guided percutaneous coronary intervention without contrast administration in advanced renal failure: a feasibility, safety, and outcome study. European Heart Journal 2016;37:3090-5.

96. Sacha J, Gierlotka M, Feusette P, et al. Ultra-low contrast coronary angiography and zero-contrast percutaneous coronary intervention for prevention of contrast-induced nephropathy: step-by-step approach and review. Postepy Kardiol Interwencyjnej 2019;15:127-136.

97. van der Wal WM, Noordzij M, Dekker FW, et al. Full loss of residual renal function causes higher mortality in dialysis patients; findings from a marginal structural model. Nephrol Dial Transplant 2011;26:2978-83.

98. Karimi Galougahi K, Mintz GS, Karmpaliotis D, et al. Zero-contrast percutaneous coronary intervention on calcified lesions facilitated by rotational atherectomy. Catheter Cardiovasc Interv 2017;90:E85-9.

99. Azzalini L, Laricchia A, Regazzoli D, et al. UltraLow Contrast Percutaneous Coronary Intervention to Minimize the Risk for Contrast-Induced Acute Kidney Injury in Patients With Severe Chronic Kidney Disease. J Invasive Cardiol 2019;31:176-82.

100. Goto K, Zhao Z, Matsumura M, et al. Mechanisms and Patterns of Intravascular Ultrasound In-Stent Restenosis Among Bare Metal Stents and First- and Second-Generation Drug-Eluting Stents. Am J Cardiol 2015;116:1351-7.
101.Song L, Mintz GS, Yin D, et al. Characteristics of early versus late in-stent restenosis in second-generation drugeluting stents: an optical coherence tomography study. EuroIntervention 2017;13:294-302.

102. Souteyrand G, Amabile N, Mangin L, et al. Mechanisms of stent thrombosis analysed by optical coherence tomography: insights from the national PESTO French registry. Eur Heart J 2016;37:1208-16.

103. Qiu F, Mintz GS, Witzenbichler B, et al. Prevalence and Clinical Impact of Tissue Protrusion After Stent Implantation: An ADAPT-DES Intravascular Ultrasound Substudy. JACC Cardiovasc Interv 2016;9:1499-507.

104. Guo N, Maehara A, Mintz GS, et al. Incidence, mechanisms, predictors, and clinical impact of acute and late stent malapposition after primary intervention in patients with acute myocardial infarction: an intravascular ultrasound substudy of the Harmonizing Outcomes with Revascularization and Stents in Acute Myocardial Infarction (HORIZONS-AMI) trial. Circulation 2010;122:1077-84.

105.Im E, Kim BK, Ko YG, et al. Incidences, predictors, and clinical outcomes of acute and late stent malapposition detected by optical coherence tomography after drugeluting stent implantation. Circ Cardiovasc Interv 2014;7:88-96.

106. Hassan AK, Bergheanu SC, Stijnen T, et al. Late stent malapposition risk is higher after drug-eluting stent compared with bare-metal stent implantation and associates with late stent thrombosis. Eur Heart J 2010;31:1172-80.

107. Won H, Shin DH, Kim BK, et al. Optical coherence tomography derived cut-off value of uncovered stent struts to predict adverse clinical outcomes after drug-eluting stent implantation. Int J Cardiovasc Imaging 2013;29:1255-63.

108. Armstrong EJ, Feldman DN, Wang TY, et al. Clinical presentation, management, and outcomes of angiographically documented early, late, and very late stent thrombosis. JACC Cardiovasc Interv 2012;5:131-40.

109. Agewall S, Beltrame JF, Reynolds HR, et al. ESC working group position paper on myocardial infarction with nonobstructive coronary arteries. Eur Heart J 2017;38:143-53.

110.Pasupathy S, Air T, Dreyer RP, et al. Systematic review of patients presenting with suspected myocardial infarction and nonobstructive coronary arteries. Circulation 2015;131:861-70.

111. Opolski MP, Spiewak M, Marczak M, et al. Mechanisms of Myocardial Infarction in Patients With Nonobstructive Coronary Artery Disease: Results From the Optical Coherence Tomography Study. JACC Cardiovasc Imaging 
2019;12:2210-21.

112.van der Sijde JN, Karanasos A, van Ditzhuijzen NS, et al. Safety of optical coherence tomography in daily practice: a comparison with intravascular ultrasound. Eur Heart J Cardiovasc Imaging 2017;18:467-74.

113. Alberti A, Giudice P, Gelera A, et al. Understanding the

Cite this article as: Nagaraja V, Kalra A, Puri R. When to use intravascular ultrasound or optical coherence tomography during percutaneous coronary intervention? Cardiovasc Diagn Ther 2020;10(5):1429-1444. doi: 10.21037/cdt-20-206 economic impact of intravascular ultrasound (IVUS). The European Journal of Health Economics 2016;17:185-93. 114. Maehara A, Weisz G, Neumann FJ, et al. TCT-68 Does IVUS Reduce Stent Thrombosis with DES? Two-year results from the prospective, multicenter ADAPT-DES study. J Am Coll Cardiol 2013;62:B21. 